Nova Southeastern University

Florida

NOVA SOUTHEASTERN

UNIVERSITY

NSUWorks

Marine \& Environmental Sciences Faculty Articles Department of Marine and Environmental Sciences

$3-1-2013$

\title{
Synthesizing Larval Competence Dynamics and Reef-Scale Retention Reveals a High Potential for Self-recruitment in Corals
}

Joana Figueiredo

James Cook University - Townsville, Australia, jigueiredo@nova.edu

Andrew H. Baird

James Cook University - Townsville, Australia

Sean R. Connolly

James Cook University - Townsville, Australia

Find out more information about Nova Southeastern University and the Halmos College of Natural Sciences and Oceanography.

Follow this and additional works at: https://nsuworks.nova.edu/occ_facarticles

Part of the Marine Biology Commons, and the Oceanography and Atmospheric Sciences and Meteorology Commons

\section{NSUWorks Citation}

Joana Figueiredo, Andrew H. Baird, and Sean R. Connolly. 2013. Synthesizing Larval Competence Dynamics and Reef-Scale Retention Reveals a High Potential for Self-recruitment in Corals .Ecology, (3) : 650 -659. https://nsuworks.nova.edu/ occ_facarticles/421. 


\title{
Synthesizing larval competence dynamics and reef-scale retention reveals a high potential for self-recruitment in corals
}

\author{
Joana Figueiredo, ${ }^{1,3}$ Andrew H. Baird, ${ }^{1}$ and Sean R. Connolly ${ }^{1,2}$ \\ ${ }^{1}$ ARC Centre of Excellence for Coral Reef Studies, James Cook University, Townsville, QLD 4811 Australia \\ ${ }^{2}$ School of Marine and Tropical Biology, James Cook University, Townsville QLD 4811 Australia
}

\begin{abstract}
Many organisms have a complex life-cycle in which dispersal occurs at the propagule stage. For marine environments, there is growing evidence that high levels of recruitment back to the natal population (self-recruitment) are common in many marine organisms. For fish, swimming behavior is frequently invoked as a key mechanism allowing high self-recruitment. For organisms with weak-swimming larvae, such as many marine invertebrates, the mechanisms behind self-recruitment are less clear. Here, we assessed whether the combination of passive retention of larvae due to re-circulation processes near reefs, and the dynamics of settlement competence, can produce the high levels of self-recruitment previously estimated by population genetic studies for reef-building corals. Additionally, we investigated whether time to motility, which is more readily measurable than competence parameters, can explain the between-species variation in self-recruitment. We measured the larval competence dynamics of broadcast-spawning and brooding corals and incorporated these in a model of larval retention around reefs to estimate the potential for self-recruitment and assess its variation among species and reefs. Our results suggest that the larvae of many corals, even those with an obligate planktonic phase, develop with sufficient rapidity to allow high levels of self-recruitment, particularly for reefs with long water retention times. Time to motility explained $77-86 \%$ of the between-species variation in potential self-recruitment in scenarios with a realistic range of retention times. Among broadcast spawners, time to motility was strongly and positively correlated with egg size, i.e., broadcast spawner species with small eggs developed more rapidly and exhibited greater potential for self-recruitment. These findings suggest that, along with water retention estimates, easy-to-measure species traits, such as egg size and time to motility, may be good predictors of potential self-recruitment, and therefore may be used to characterize the spectrum of self-recruitment in corals.
\end{abstract}

Key words: competence; connectivity; coral reefs; development; dispersal; embryogenesis; localized recruitment; spawning time.

\section{INTRODUCTION}

One of the major goals in ecology is to understand patterns of dispersal and connectivity among local populations. Dispersal patterns shape species' distributions (Wilson et al. 2009, Kramer et al. 2011), abundance (Hogg and Daane 2010, Fennell et al. 2012), and population persistence (Campbell Grant et al. 2010, Salomon et al. 2010), and determine the potential for populations to adapt (Hellberg 1994, Garant et al. 2007). Understanding dispersal patterns is therefore essential to answering many ecological and evolutionary questions (Sexton et al. 2009) as well as predicting the impacts of habitat fragmentation and designing protected areas (Born et al. 2008, Edwards et al. 2010). A large proportion of plants and animals have a relatively sedentary adult stage, with dispersal occurring mainly at the propagule stage. Propagules

Manuscript received 10 May 2012; revised 26 September 2012; accepted 2 October 2012. Corresponding Editor: R. B. Aronson.

${ }^{3}$ E-mail: joana.figueiredo@jcu.edu.au are often dispersed passively by wind (e.g., freshwater invertebrates [Vanschoenwinkel et al. 2008]), rivers (e.g., riparian plants [Merritt et al. 2010]), ocean currents (e.g., hydrothermal vents [Adams et al. 2012]), and animals (e.g., seeds of tropical trees dispersed by primates [Chapman and Russo 2006]) The degrees of selfrecruitment and long-distance dispersal also depend upon characteristics of the propagule, such as mass, buoyancy, shape, motility, rates of development, and sensory abilities (Nathan and Muller-Landau 2000, Dixson et al. 2011).

A growing body of research on marine benthic organisms indicates that a large proportion of larvae may be retained locally, even in species with the potential for long distance dispersal (Swearer et al. 2002, Cowen and Sponaugle 2009). For instance, markrecapture and parentage analysis of reef fishes indicate remarkably high (5-72\%) levels of recruitment back to the natal population (hereafter "self-recruitment" [Jones et al. 2009]). Similarly, $90 \%$ of a larval cohort of the intertidal mussel Mytilus galloprovincialis recruited within a $5 \mathrm{~km}$ radius of the source population (McQuaid 
and Phillips 2000). Other evidence for a high degree of self-recruitment in marine populations includes highly subdivided genetic population structure (e.g., corals [Saavedra-Sotelo et al. 2011]), persistence of endemic species with pelagic larvae on small isolated islands (e.g., angelfishes [Hobbs et al. 2010]), persistence of introduced species (e.g., lionfish [Whitfield et al. 2007]) and a positive correlation between larval production and larval supply at the regional scale (e.g., coral reef fishes [Grorud-Colvert and Sponaugle 2009]).

Field surveys and genetic studies suggest that corals are among the marine species likely to have a substantial level of self-recruitment and limited dispersal (Ayre and Hughes 2000, Gilmour et al. 2009). In contrast, existing models of coral dispersal still predict that coral populations have a massive export of planktonic propagules from the patch of origin, followed by wide dispersal, with the result that populations are connected over large spatial scales (Kininmonth et al. 2010). This discrepancy suggests that the biological assumptions made in such models may omit important factors that promote self-recruitment in corals. For other organisms, such as reef fish, swimming behavior has been identified as a key mechanism for self-recruitment, because larvae can sense reefs (Wright et al. 2005) and swim upstream toward them (Leis et al. 2007). However, coral larvae are poor swimmers and thus unlikely to be able to swim against currents (see Plate 1). One of the biological factors that may influence self-recruitment rates in corals is intra-cohort variation in larval settlement dynamics. Existing dispersal models assume that all larvae acquire the capacity to settle (hereafter "competence") at a fixed time, when, in fact, there is considerable variation among and within species in the time to acquire competence. Thus, the assumption of a fixed competence time may lead to underestimates of self-recruitment (Connolly and Baird 2010). In addition, because the rate at which competence is acquired is often of a similar order to particle retention times around many reefs (0.56 days; Black et al. 1990, Kraines et al. 1998, Paris and Cowen 2004, Cetina-Heredia and Connolly 2011), small differences in the estimated time at which competence is acquired have the potential to materially alter projected patterns of coral dispersal and connectivity (Connolly and Baird 2010).

In this study, we calibrate models of larval competence dynamics, and integrate them with estimates of passive retention of larvae around the reef of origin, to evaluate how larval competence dynamics and reef-scale physical retention mechanisms around reefs interact to influence between-species variation in self-recruitment in corals. Also, because direct estimates of competence parameters are only available for a handful of species, we investigate whether time to motility, which is a more easily-obtained measure of development time, explains the between-species variation that we document, and therefore can provide a means of indirectly estimating potential self-recruitment at the assemblage level.
Specifically, we first quantified the frequency distribution of settlement of eight coral species with different modes of larval development. Second, we used these data to calibrate a model of larval self-recruitment, and we estimated the proportion of larvae that would successfully acquire competence while retained on the natal reef for a range of reef retention scenarios. Third, we assessed the relationship between time to motility and potential self-recruitment across each of our retention scenarios. Finally, we calibrate a relationship between egg size and time to motility in broadcastspawning species: this calibration makes possible the approximation of time to motility for a broad range of coral species for which direct observations of time to motility are unavailable. Our results reveal an unexpectedly high capacity for passive self-recruitment in corals, and indicate that a large proportion of the interspecific variation in this capacity can be explained by time to motility. These results indicate that interspecific variation in local retention dynamics can be approximated at the assemblage level without the need to calibrate competence dynamics separately for hundreds of coral species.

\section{Methods \\ Frequency distribution of settlement}

Gametes of six broadcast-spawning species (Acropora humilis, A. gemmifera, A. millepora, A. valida, Goniastrea retiformis, and Platygyra daedalea) were collected and mixed (separately by species) from four to six colonies each. Embryos and larvae were reared between $26^{\circ}$ and $28^{\circ} \mathrm{C}$ under white fluorescent light with a $12: 12 \mathrm{~h}$ light : dark photoperiod as described in Babcock et al. (2003). To estimate the potential for self-recruitment, we quantified the proportion of larvae settling over time from single cohorts of each of the six broadcastspawning species. The larvae of most corals will only begin metamorphosis when stimulated by chemical cues released by suitable settlement substrates (Morse et al. 1996). Thus, we simulated conditions under which larvae were retained near the reef of origin by keeping larvae constantly exposed to a suitable settlement substratum. Note that this experimental approach differs from the approach used by Connolly and Baird (2010), who assayed the competence of larvae maintained in the absence of cues, simulating conditions experienced in the plankton. Once larvae had reached the gastrula stage, approximately $12-24 \mathrm{~h}$ post-fertilization depending on species, between 330 and 1200 larvae were counted into two replicate glass aquaria containing two clay paving tiles $(5 \times 5 \times 1 \mathrm{~cm})$ as a settlement substratum. These tiles had been conditioned for six weeks at $3 \mathrm{~m}$ on the reef crest at Orpheus Island, Great Barrier Reef, Australia ( $\left.18^{\circ} 62^{\prime} \mathrm{S}, 146^{\circ} 49^{\prime} \mathrm{E}\right)$. The tiles were removed and replacements introduced $4,7,10$, and 14 days following spawning. All tile surfaces were censused in a water bath using a stereo-dissecting microscope and the number of larvae completing 
metamorphosis (henceforth termed "settlement") was counted. Settlement was defined as the deposition of a basal plate (following Baird and Babcock [2000]).

To establish the frequency distribution of settlement in the brooding species Seriatopora hystrix and Stylophora pistillata, freshly released larvae were collected at dawn from adult colonies maintained in a flow-through aquarium with a larval catcher on the outflow, and 60 larvae were introduced into each of two clear plastic jars per species containing unfiltered seawater. The numbers of larvae that had settled on the side of the jars were counted at intervals of varying duration (2.5-96 hours; intervals increased as cohorts aged and competence dynamics changed more slowly). Unlike the Acroporidae and Faviidae, most pocilloporids, including $S$. pistillata, do not require pre-conditioned surfaces to induce metamorphosis (Baird and Morse 2004). All experiments were performed in a constant-temperature room (range of $26^{\circ}$ to $28^{\circ} \mathrm{C}$ ) under a combination of blue actinic and white light with a 12:12 h light: dark photoperiod.

\section{Estimating competence and mortality}

To predict the potential for self-recruitment, we first estimated competence and survival parameters for the eight species. To do so, we modified the model of Connolly and Baird (2010) to characterize the settlement dynamics of a cohort continuously exposed to a settlement cue, such that larvae could settle immediately upon attaining competence. We then estimated competence and survival parameters using our experimental data. Finally, we combined these estimates with estimates of larval flushing rates from Black et al. (1990), to estimate the probability that larvae attain competence prior to being flushed from the reef. Modeling was performed in software R (see code in Supplement).

Connolly and Baird (2010) assumed that the planktonic larval phase is divided into three stages: precompetent (larvae that have not yet acquired the capacity to settle), competent (larvae that will settle and metamorphose in the presence of a suitable substrate), and post-competent (larvae that have lost the capacity to settle, but remain alive). In our experiment, larvae are continuously exposed to a settlement cue, so we assume that they will settle as soon as they become competent. Consequently, our cohort is divided into two stages: pre-competent larvae and settled larvae. For the pre-competent stage, larvae acquire competence at per capita rate $\alpha(t)$, and suffer mortality at per capita rate $\mu(t)$ :

$$
\frac{d L_{1}(t)}{d t}=-\alpha(t) L_{1}(t)-\mu(t) L_{1}(t)
$$

where $L_{1}(t)$ is the number of pre-competent larvae at time $t$. Once larvae acquire competence, they settle. Thus, the subpopulation that has settled has the following dynamics:

$$
\frac{d S(t)}{d t}=\alpha(t) L_{1}(t)
$$

where $S(t)$ is the cumulative number of settled larvae after time $t$. Initially, all larvae are in the pre-competent state

$$
L_{1}(0)=L_{0} \quad S(0)=0 .
$$

Following Connolly and Baird (2010), we assume that there is a minimum pre-competent period, $t_{\mathrm{c}}$, required for individuals to complete embryogenesis and develop the structures needed for settlement, and after that, larvae acquire competence at a constant per capita rate a. Because individuals in our replicates also suffer mortality, we model mortality as occurring at a constant per-capita rate $m$. With these assumptions, we can solve Eq. 1 to obtain the cumulative number of settlers as a function of time:

$$
S(t)=\frac{a}{a+m} L_{0} e^{-m t_{\mathrm{c}}}\left(1-e^{-(a+m)\left(t-t_{\mathrm{c}}\right)}\right)
$$

when $t>t_{\mathrm{c}}$, and zero otherwise. Therefore, the number of larvae settling between time instances $t_{i}$ and $t_{j}$ is

$$
s_{i j}=S\left(t_{j}\right)-S\left(t_{i}\right)=\frac{a}{a+m} L_{0} e^{a t_{c}}\left[e^{-(a+m) t_{i}}-e^{-(a+m) t_{j}}\right]
$$

where $t_{j}>t_{i} \geq t_{\mathrm{c}}$.

Eqs. 2 and 3 are deterministic, and therefore represent the dynamics of the mean number of settlers. To estimate competence parameters from empirical data, we therefore incorporate random variation in the observed numbers of settlers. Specifically, because larvae either settle between $t_{i}$ and $t_{j}$, or they do not, the number of actual larvae settling between $t_{i}$ and $t_{j}$, which we here designate $k$, is a binomially distributed random variable:

$$
P_{i j}(k)=\left(\begin{array}{c}
L_{0} \\
k
\end{array}\right)\left(\frac{s_{i j}}{L_{0}}\right)^{k}\left(\frac{1-s_{i j}}{L_{0}}\right)^{L_{0}-k}
$$

where $s_{i j}$ is the expected number of larvae settling between $t_{i}$ and $t_{j}$, as given by Eq. 3. We use maximum likelihood methods to estimate the competence and mortality parameters $a, m$, and $t_{\mathrm{c}}$, based on the number settling in each replicate aquarium for each census interval. When peak competence occurred during the first sampling period, Connolly and Baird (2010) sometimes obtained two likelihood maxima, corresponding to very different values of the time delay parameter $t_{\mathrm{c}}$. Therefore, to improve the statistical properties of our estimates, we constrained $t_{\mathrm{c}}$ so that it could not take on unrealistically small values. Specifically, larvae always become motile before they attain competence to settle (Heyward and Negri 1999), so we recorded the time at which larvae became motile, and we constrained $t_{\mathrm{c}}$ to be later than time to motility in the maximum likelihood estimation procedure. 


\section{Estimating local retention}

To estimate the proportion of larvae attaining competence prior to being flushed from the reef, we modified the model in Eq. 1 to incorporate flushing of larvae:

$$
\begin{aligned}
& \frac{d L_{1}^{*}(t)}{d t}=-a L_{1}^{*}(t)-m L_{1}^{*}(t)-\gamma L_{1}^{*}(t) \\
& \frac{d S(t)}{d t}=a L_{1}^{*}(t)
\end{aligned}
$$

where the superscript * denotes pre-competent larvae that have not yet been flushed from the reef, $a$ and $m$ are the maximum likelihood estimates obtained from analysis of our data, and $\gamma$ is the flushing rate for a reef (whose reciprocal is the mean particle retention time around a reef). We considered 10 different flushing-rate scenarios that Black et al. (1990) previously estimated for 10 reefs with different dimensions and circulation regimes in the Great Barrier Reef (GBR; Appendix A) based on the particular conditions (free stream current, reef dimensions, tidal excursion, shelf depth, residual current in the lee of the reef, and the lagoon volume) prevailing when oceanographic measurements were made (see Appendix A and Black et al. [1990] for details). While flushing rates vary geographically and temporally, the range of flushing rates reported by Black et al. (1990), and used here, allows us to explore how between-species variation in self-recruitment changes across a broad range of residence times (0.7-16.3 d). This range is typical of patchy reefs, fringing reefs, lagoons, and even some atolls, in many reef systems (e.g., 0.8-22.8 d on the GBR [Andutta et al. 2012], 5-17 $\mathrm{d}$ in the Caribbean [Paris and Cowen 2004], 0.8-2 $\mathrm{h}$ in Oahu, Hawaii [Leis 1982], 2-9.3 h in Miyako Island, Japan [Kraines et al. 1998], and 0.25, 10, 12, and $16 \mathrm{~d}$ at Moorea, Tahiti, Kiribati, and Tuamoto, respectively [Delesalle and Sournia 1992]). Note, however, that some large lagoons and most atolls have much greater residence times (Delesalle and Sournia 1992, Tarinville et al. 1997). At these latter locations, high retention and self-seeding are widely accepted to be common, regardless of species, and therefore are not considered here.

\section{Time to motility and potential self-recruitment}

The eggs and larvae of all coral species studied were observed every $6 \mathrm{~h}$ to determine the time post-spawning when $50 \%$ of the larvae first become motile. Motility in coral larvae begins as spinning around the axis in the spherical larvae post-gastrulation, followed by more active and directional movement of a pear-shaped larva (planula) through the water column. To assess if time to motility is a good predictor of the proportion of larvae that successfully attain competence while retained (i.e., is a good proxy for potential self-recruitment), we regressed, for each flushing scenario, the estimated proportion of larvae that successfully attain competence while retained against time to motility, using the estimates of the eight species. When a linear regression was not a good fit, we used an asymptotic regression. The uncertainty around each individual estimate of retention time was not homogeneous (i.e., the estimated proportions of some species were more uncertain than others), and, where estimated retention was low, the uncertainty tended to be skewed. Therefore, to obtain a robust estimate of uncertainty around the overall relationship between retention and time to motility, we used a hierarchical non-parametric bootstrap approach (Efron and Tibshirani 1993). Firstly, for each species, we bootstrap resampled the replicate settlement tiles for each day (two replicates per day), and re-fit the model to each bootstrap replicate. We then used the competence and mortality estimates from the analysis of each bootstrap sample to produce a bootstrap distribution for the proportion of larvae attaining competence prior to flushing for each species. Then, we sampled one of these values from each individual species' bootstrap distribution, and did a regression between time to motility and the proportion attaining competence while retained. For the within-species bootstrap distributions, there was a relatively small number of possible combinations of tiles in some cases so we enumerated all of these possible combinations, and fit the model to each of them (rather than sampling with replacement, as in conventional bootstrapping). For the higher-level bootstrap (the among-species regression), we analyzed 1000 bootstrap samples by drawing a value for each species at random from each of their respective speciesspecific bootstrap distributions. We then used percentiles of the bootstrap distribution of the regression slopes to place $95 \%$ confidence intervals on the regression line.

\section{Egg size and time to motility}

For broadcast spawners, time to motility cannot be readily measured: one needs to spawn corals, fertilize eggs, rear larvae in controlled conditions, and perform regular observations throughout this period. Consequently, time to motility has only been recorded for 29 species (A. H. Baird, unpublished data). Therefore, for spawning corals, we evaluate whether time to motility can be predicted from a more readily measurable species trait, namely egg size. To assess the relationship between egg size and time to motility for broadcast spawner species, we analyzed previously unpublished data on motility for 20 species collected by one of us (A. H. Baird) over multiple spawning events between 1996 and 2004. For each species, gametes from four to six colonies were mixed, and embryos and larvae were cultured between $26^{\circ} \mathrm{C}$ and $28^{\circ} \mathrm{C}$ under white fluorescent light with a 12:12 h light: dark photoperiod as described in Babcock et al. (2003). Egg size was measured approximately 30 minutes after release to allow the eggs to become spherical. The eggs and larvae of all coral species studied were observed every $6 \mathrm{~h}$ to determine the 
A) Acropora gemmifera

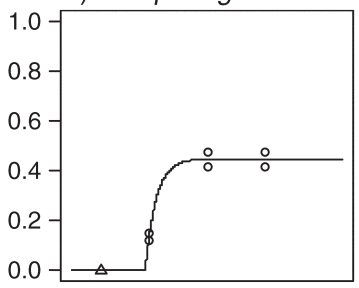

C) Acropora millepora

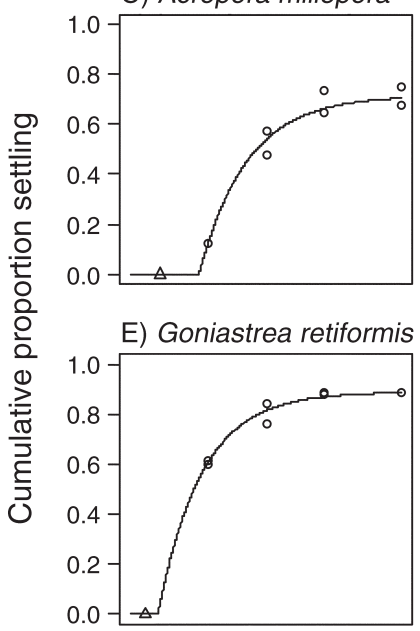

G) Seriatopora hystrix

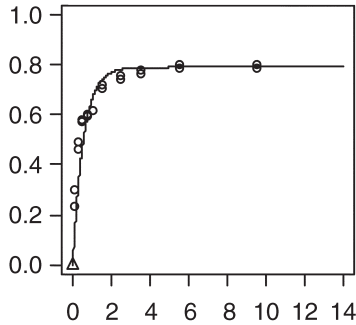

Time

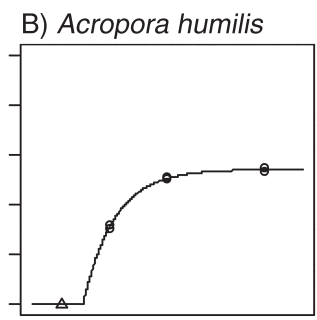

D) Acropora valida
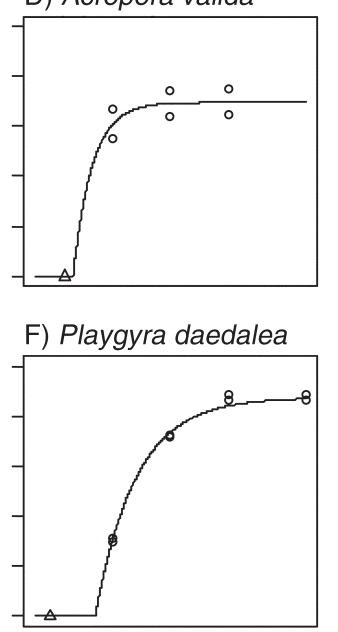

H) Stylophora pistillata

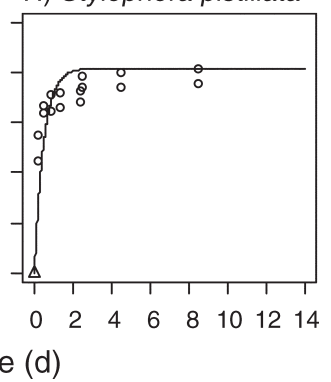

FIG. 1. Cumulative proportion of larvae settling through time for the eight coral species studied. Each circle represents the updated measure of cumulative settlement for each replicate (i.e., the leftmost circles represent the number settling on the first tile deployed, the next circles to the right show the sum of the numbers settling on the first and second tiles deployed, etc.). The triangle indicates onset of motility $\left(t_{\mathrm{m}}\right)$, and the solid line is the predicted cumulative settlement from the fitted competence and survival model, obtained by integrating Eq. 5b and normalizing by $L_{0}$ (the number or pre-competent larvae at time 0).

time post-spawning when $\sim 50 \%$ of the larvae first become motile. The relationship between egg size (mean diameter) and time to motility was assessed with linear regression.

\section{RESULTS}

Striking differences were apparent in the patterns of settlement among the species (Fig. 1). Mean time to competence of A. millepora, A. gemmifera, A. humilis, and Platygyra daedalea occurred more than four days after spawning (Table 1, Fig. 1A-C, F). In contrast, in Acropora valida and Goniastrea retiformis, the mean time to competence was before day four (Table 1, Fig. $1 \mathrm{D}$ and $\mathrm{E})$. The minimum pre-competent period $\left(t_{\mathrm{c}}\right)$ was less than four days in all species (Table 1). Additionally, considerable variation in the age at settlement was apparent between individual larvae within all cohorts. For example, some A. millepora larvae settled more than 10 days after others in the cohort (Fig. 1C). This variation was less pronounced in $A$. valida and $A$. gemmifera where settlement was more synchronous and concentrated in the week following spawning (Fig. 1A and $\mathrm{D}$ ). The larvae of the brooding species settled very rapidly. Within $6 \mathrm{~h}$ of release, nearly half of the cohorts of both brooding species had settled (Fig. $1 \mathrm{G}$ and $\mathrm{H}$ ). The cumulative proportion of the initial cohort that settled by the end of the study varied from $45 \%$ in $A$. gemmifera to $>80 \%$ in G. retiformis and P. daedalea (Fig. 1); the remainder either died or failed to attain competence during the 14-day experiment.

Motile larvae were first observed in all Acropora species at $36 \mathrm{~h}$ (Appendix B). The larvae of P. daedalea and $G$. retiformis developed more quickly than the Acropora, being motile after $18 \mathrm{~h}$ (Appendix B). The larvae of S. hystrix and S. pistillata were motile on release (Appendix B). Time to motility was a good predictor of potential for self-recruitment, explaining $77-86 \%$ of the variation (Fig. 2). Species with shorter times to motility are more likely to recruit locally; however, for the broadcast spawners, the strength of this relationship depends on the retention time of individual reefs (Fig. 2). Estimates of water retention around reefs vary enormously, from less than a day at Wheeler Reef to more than two weeks at Davies Reef for the scenarios modeled in Black et al. (1990) (Appendix A). If retention time is toward the high end of this range (Fig. 2A-E), and therefore similar to or greater than the mean time to competence of the spawners (i.e., approximately 3-6 days; Table 1), a large proportion of the larvae of all species (20-80\%), are predicted to be retained. However, spawning species with a shorter time to motility, such as the faviids, G. retiformis and P. daedalea, are predicted to have greater potential for self-recruitment than the Acropora species (Fig. 2A-E). As retention time shortens further, the brooders maintain their potential for high self-recruitment, but the differences in selfrecruitment among broadcast spawners diminish, as most larvae are flushed away from the reef before attaining competence (Fig. 2F-J).

In broadcast spawners, egg size on release is an excellent predictor of time to motility $\left(R^{2}=0.80\right.$, Fig. 3; see Appendix B for summary data).

\section{DisCUSSION}

Under retention scenarios typical of many reefs, a large proportion of the recruits of many species are likely to be of local origin. For most residence times 
TABLE 1. Estimates of the competence model parameters: per capita rate of acquisition of competence when $t>t_{\mathrm{c}}(a)$, time to competence $\left(t_{\mathrm{c}}\right)$, and per capita rate of mortality $(m)$, along with estimated mean time to acquire competence $\left(t_{\mathrm{c}}+1 / a\right)$.

\begin{tabular}{|c|c|c|c|c|}
\hline \multirow[b]{2}{*}{ Species } & \multicolumn{3}{|c|}{ Model parameters } & \multirow{2}{*}{$\begin{array}{l}\text { Mean time } \\
\text { to competence (d) }\end{array}$} \\
\hline & $\hat{a}\left(\mathrm{~d}^{-1}\right)$ & $\hat{t}_{\mathrm{c}}(\mathrm{d})$ & $\hat{m}\left(\mathrm{~d}^{-1}\right)$ & \\
\hline Acropora gemmifera & $1.596(1.283-2.056)$ & $3.802(3.753-3.846)$ & $0.183(0.171-0.197)$ & 4.43 \\
\hline A. humilis & $0.476(0.315-0.584)$ & $2.61(2.086-2.858)$ & $0.1379(0.112-0.156)$ & 4.71 \\
\hline A. millepora & $0.348(0.321-0.376)$ & $3.526(3.455-3.589)$ & $0.054(0.046-0.062)$ & 6.4 \\
\hline A. valida & $0.89(0.586-1.294)$ & $1.945(1.5-2.535)$ & $0.121(0.101-0.146)$ & 3.07 \\
\hline Gonistrea retiformis & $0.411(0.371-0.452)$ & $1.409(1.141-1.645)$ & $0.0313(0.023-0.039)$ & 3.85 \\
\hline Platvgvra daedalea & $0.447(0.418-0.478)$ & $3.087(3.005-3.163)$ & $0.0255(0.019-0.032)$ & 5.33 \\
\hline Seriatopora hystrix & $1.439(1.052-1.931)$ & $7.2 \times 10^{-10}(0-0.011263)$ & $0.381(0.064-0.701)$ & 0.69 \\
\hline Stylophora pistillata & $1.732(1.4-2.116)$ & $7.2 \times 10^{-10}(0-0.00539)$ & $0.384(0.136-0.631)$ & 0.58 \\
\hline
\end{tabular}

Note: Values in parentheses indicate the $95 \%$ profile likelihood intervals of the parameters.

studied here, a substantial number of larvae (approximately $5-80 \%$ of the initial cohort; Fig. 2) become competent before being transported away from the reef, and are, therefore, likely to recruit locally. In addition, although the variation in acquisition of competence within a cohort often indicates that more than half of the larvae are flushed from the reef before attaining competence, only a small fraction of these larvae are likely to remain alive and competent long enough to be captured by a downstream reef (Black 1993, Graham et al. 2008, Connolly and Baird 2010). These findings suggest that cohorts of recruits may be dominated by self-recruiting individuals in many circumstances. Our results underscore the importance of resolving both the physical mechanisms that influence reef-scale particle retention, and the dynamics of survival and the acquisition of competence, in order to model potential self-recruitment in corals. The inclusion of larval competence dynamics is essential to explain interspecific variation in self-recruitment. Moreover, we found that

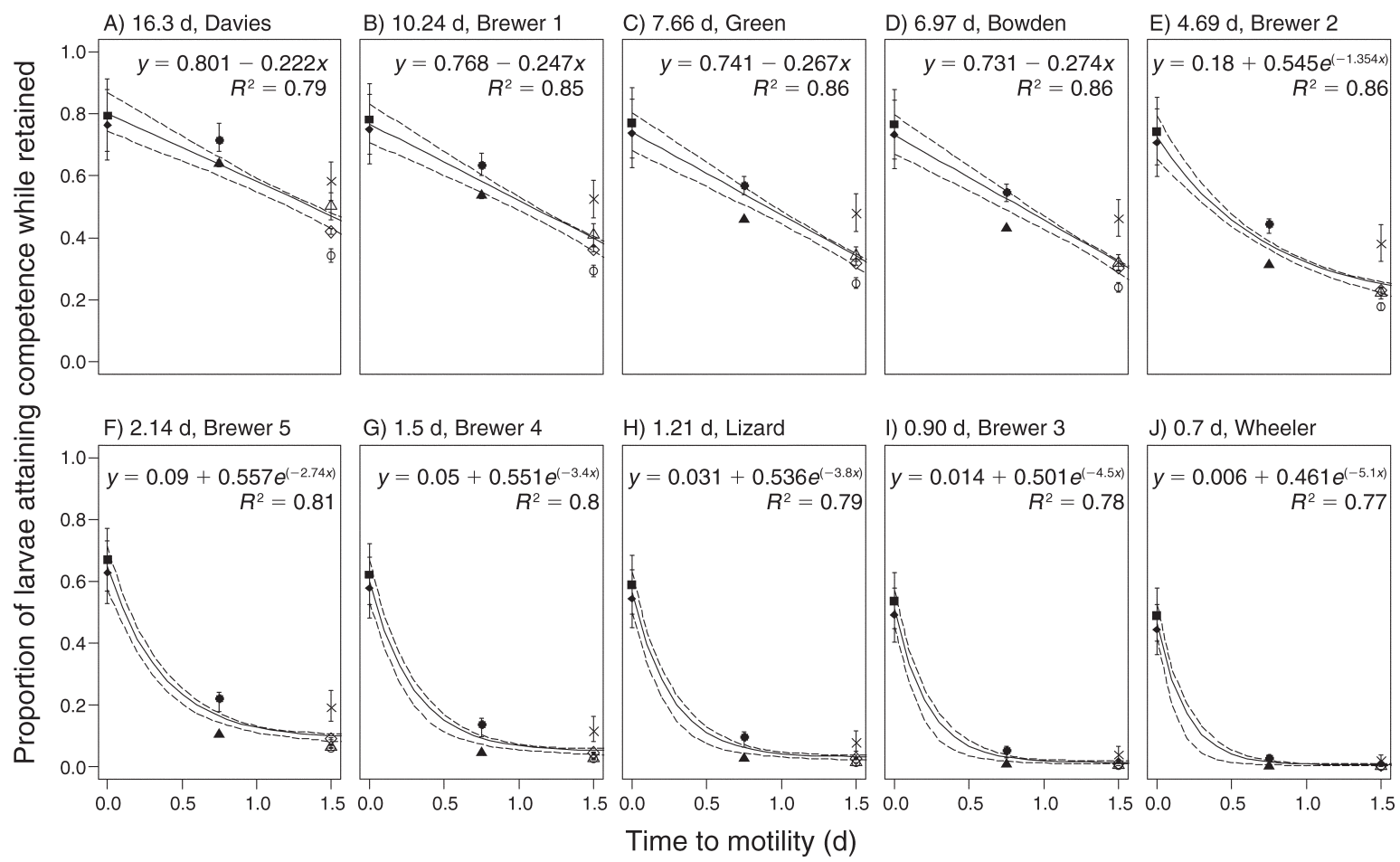

FIG. 2. Effect of time to motility on the proportion of larvae alive and competent while still in the retention zone over a range of retention times for the eight species studied. At the top of each panel, the mean retention time (decreasing from A to J) and the name of the reef are presented. Symbols represent the estimates of the proportion of larvae alive and competent while retained for each species (solid squares, Stylophora pistillata; solid diamonds, Seriatopora hystrix; solid circles, Goniastrea retiformis; solid triangles, Platygyra daedalea; crosses, Acropora valida; open triangles, Acropora millepora; open diamonds, Acropora humilis; and open circles, Acropora gemmifera) under each retention scenario, while the error bars on the points represent the range of uncertainty of that estimate. The solid line is the line of best-fit obtained from a least-squares regression, and the dashed lines represent the $95 \%$ confidence intervals on the regression line. 


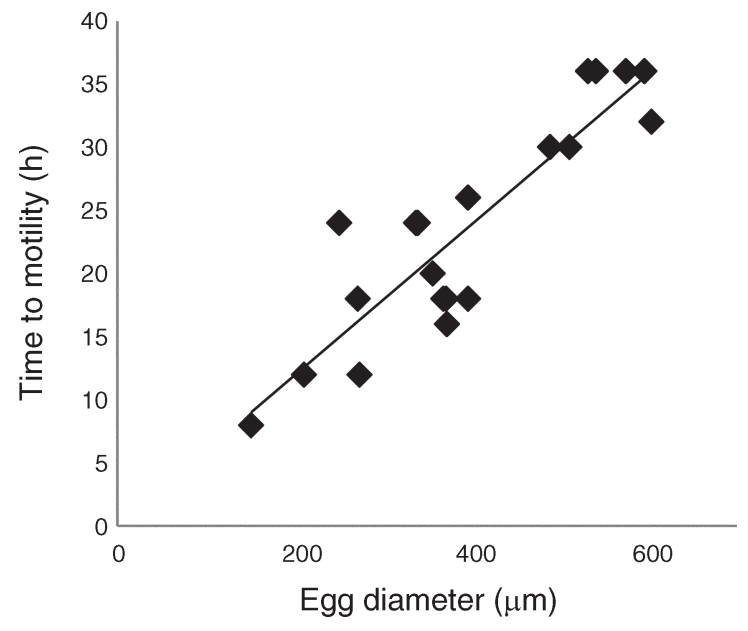

FIG. 3. Relation between egg size (es) and time to motility $\left(t_{\mathrm{m}}\right)$ of the broadcast-spawning 20 species listed in Appendix B. Each square represents a species, and the line is the best-fit line from an ordinary least-squares regression $\left(t_{\mathrm{m}}=0.0596 \mathrm{es}+\right.$ $0.067, R^{2}=0.80$ ).

time to motility explained a large proportion of the interspecific variation in estimated self-recruitment, and, for broadcast-spawning species in particular, egg size was an excellent predictor of time to motility. These results suggest that readily measurable species traits, coupled with estimates of particle retention times, may be sufficient for reasonable estimates of potential selfrecruitment to be made.

Estimates of water retention around reefs are most commonly within the range of $0.5-6 \mathrm{~d}$, depending on currents speed, reef shape, and vertical diffusion (Black et al. 1990, Black 1993, Cetina-Heredia and Connolly 2011). Since some larvae of brooding species settle in less than $2 \mathrm{~h}$, and typically $60 \%$ of cohorts settle within a day (Table 1, Fig. 1), the estimated proportion of larvae attaining competence while retained was high (approximately $50 \%$ ), even for residence times on the order of hours (Fig. 2). All broadcast spawners considered here had an obligatory minimum pre-competent period $\left(t_{\mathrm{c}}\right)$ of less than four days, consistent with earlier work using pre-conditioned substrata (Morse et al. 1996, Nozawa and Harrison 2002, Harrison 2006), and most settled in 3-6 d (Fig. 1). When reef-residence times were greater than, or similar to, the mean competence time, all species showed substantial $(\sim 20-80 \%)$ potential for selfrecruitment (Fig. 2). However, the potential for selfrecruitment is relatively greater in species with shorter time to motility (Fig. 2).

Despite the high potential for self-recruitment, the variation in time to settlement among individuals within cohorts indicates that there will also be some export of propagules under most retention scenarios. In some species, such as A. millepora, there was a large range in the response between individuals, with some larvae settling up to 10 days later than others in the cohort (Fig. 1). Nonetheless, these results indicate that a substantial proportion of the larvae that successfully settle and metamorphose will be of local origin in many cases. In particular, larvae that are flushed from the reef must be intercepted by a downstream reef while still alive and competent. The probability of intercepting a downstream reef may be quite low: for instance, using dispersal models and simulated reefs with the size, shape, and spacing typical of the Great Barrier Reef, Black (1993) estimated that only $\sim 1-10 \%$ of larvae are intercepted by downstream reefs, even if mortality and loss of competence are ignored. Thus, our results are consistent with the strong empirical support for the genetic subdivision found in coral populations (Ayre and Hughes 2000, van Oppen et al. 2008), including (though to a lesser extent) those with an obligatory planktonic phase (Whitaker 2004, Saavedra-Sotelo et al. 2011), such as the broadcast-spawned species examined here.

There is growing evidence from competition theory that interspecific differences in dispersal patterns can influence species coexistence, and in particular that species are more likely to coexist in metapopulations when there is trade-off between self-recruitment and competitive ability (Muko and Iwasa 2003, Salomon et al. 2010, Figueiredo and Connolly 2012). Our results suggest that such a trade-off may be present in corals. Specifically, brooding species, which have the highest self-recruitment, also are likely to be the weakest competitors: their tissue is vulnerable to digestion when in direct contact with the expanded mesenterial filaments of faviids, such as Goniastrea and Platygyra (Lang and Chornesky 1990), and they can be overtopped by the fast-growing Acropora (Stimson 1985). Among broadcast spawners, faviids are estimated in this study to have higher potential self-recruitment than Acropora. Faviids are also likely to be competitively subordinate to Acropora: although faviids can digest the tissue of Acropora along margins of contact (Lang and Chornesky 1990), their comparatively slow growth means that their digestive dominance mechanism is more likely to function as a place-holding than a displacement strategy (Lang 1973). Conversely, they are vulnerable to overtopping by the fast-growing Acropora. The latter are estimated in this study to have the lowest selfrecruitment, and they also are likely the strongest competitors, due to their greater capacity to preempt potential settlement sites and to overtop and shade out established colonies (Stimson 1985).

We estimate that competence is acquired more quickly (by up to 2 days) than previous work using many of the same species (Connolly and Baird 2010). These two studies simulated very different settlement scenarios: Connolly and Baird (2010) exposed larvae to settlement cues at fixed periods of time after spawning, having previously kept them in the absence of a settlement cue. This approach corresponds to larvae arriving at a reef after a period of time dispersing in the open ocean. In contrast, the present study mimics scenarios in which 


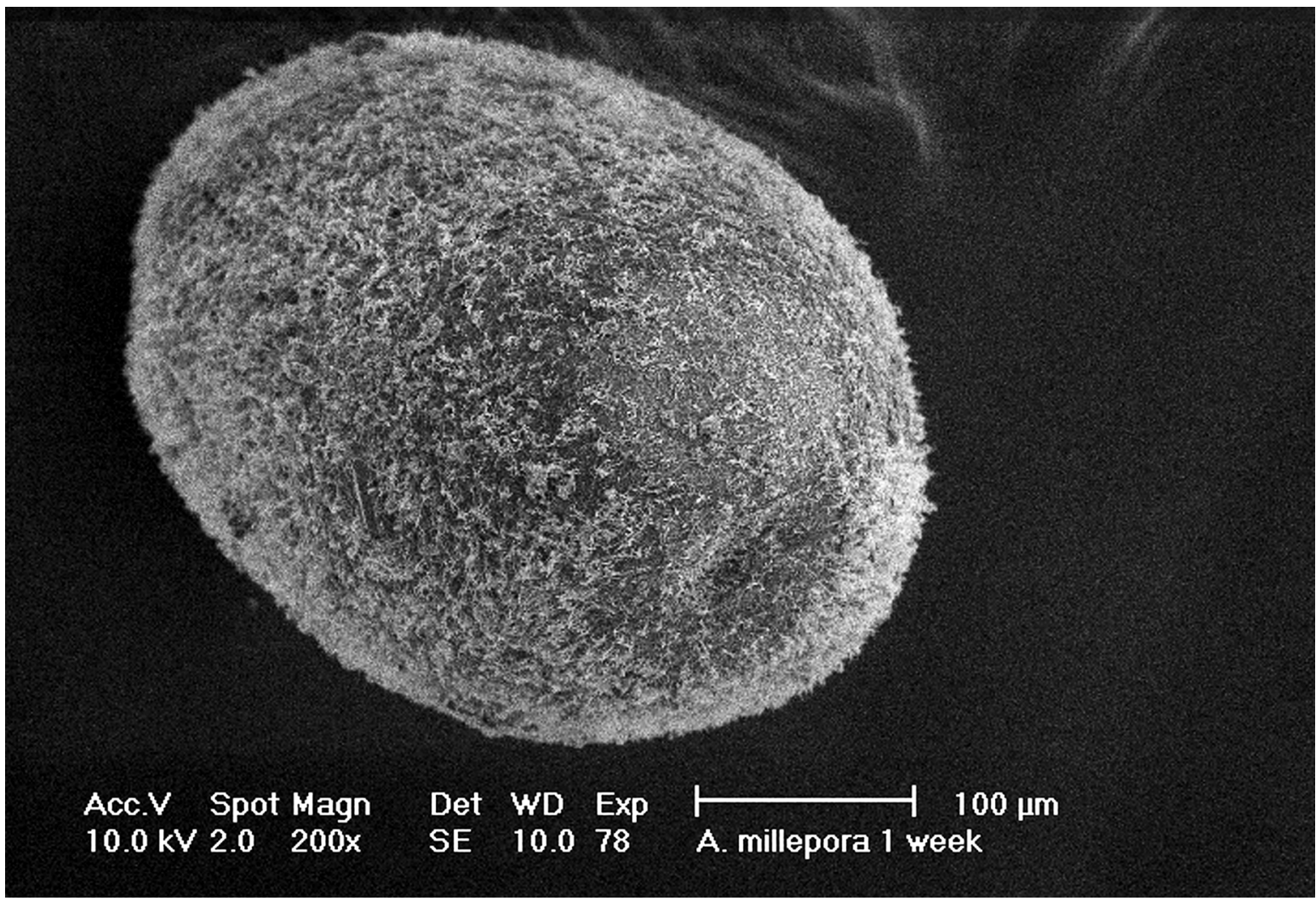

Plate 1. Coral larvae are essentially passive propagules. Larval swimming is powered only by cilia, limiting their ability to overcome turbulence and currents. Photo credit: A. H. Baird.

larvae are in close proximity to a reef (and thus constantly exposed to settlement cues) throughout early development. Despite this difference, there was a high degree of consistency in the among-species variation in mean time to acquire competence among species: estimated mean times to acquire competence were highly correlated between the two studies for the five species that were calibrated in both experiments (Spearman's $r=$ $0.77, t=2.07, P=0.13)$. Thus, the general pattern of interspecific differences documented here is robust to whether larvae are continuously exposed to settlement cues or not.

Modeling metacommunity dynamics in highly diverse systems, such as tropical rainforests or coral reefs, is a major challenge because species-by-species calibration of demographic rates is not practical. The study of coral dispersal patterns is no exception: corals are a highly diverse group, and the calibration of competence and larval survival patterns is time-consuming and costly. Therefore, models of community dynamics increasingly rely on characterizing overall distributions of demographic characteristics across an assemblage. For instance, neutral theory simply assumes that all species have the same demographic rates (Hubbell 2001). The metabolic theory of ecology links demographic parameters, such as intrinsic growth rates and carrying capacity, to readily measurable variables such as body size and temperature (Brown et al. 2004), and these relationships have been exploited to estimate population growth parameters where direct measurements are lacking for particular species of interest (e.g., the energetic efficiency of a ladybeetle [Sentis et al. 2012]). For physical retention processes affecting larvae, a substantial proportion of the variability in larval residence times around reefs appears to be predictable from broad-scale circulation features and reef dimensions (Black et al. 1990, Cetina-Heredia and Connolly 2011). In this study, we identified strong relationships between time to motility and potential self-recruitment, and, for broadcast spawners, between egg size and time to motility. These strong relationships suggest that a substantial proportion of the interspecific variation in larval competence dynamics may be similarly predictable from readily measurable characteristics of the eggs and larvae of corals.

\section{ACKNOWLedgments}

We thank the Australian Research Council (DP110101168 to A. H. Baird and DP0880544 to S. R. Connolly), the Great Barrier Reef Marine Park Authority, PADI AWARE, the NSW Zoological Society, the Australian Coral Reef Society, and James Cook University for financial support. 


\section{Literature Cited}

Adams, D. K., S. M. Arellano, and B. Govenar. 2012. Larval dispersal: vent life in the water column. Oceanography 25:256-268.

Andutta, F. P., M. J. Kingsford, and E. Wolanski. 2012. Sticky water' enables the retention of larvae in a reef mosaic. Estuarine and Coastal Shelf Science 101:54-63.

Ayre, D. J., and T. P. Hughes. 2000. Genotypic diversity and gene flow in brooding and spawning corals along the Great Barrier Reef, Australia. Evolution 54:1590-1605.

Babcock, R. C., A. H. Baird, S. Piromvaragorn, D. P. Thomson, and B. L. Willis. 2003. Identification of scleractinian coral recruits from Indo-Pacific reefs. Zoological Studies 42:211-226.

Baird, A. H., and R. C. Babcock. 2000. Morphological differences among three species of newly settled pocilloporid coral recruits. Coral Reefs 19:179-183.

Baird, A. H., and A. N. C. Morse. 2004. Induction of metamorphosis in larvae of the brooding corals Acropora palifera and Stylophora pistillata. Marine and Freshwater Research 55:469-472.

Black, K. P. 1993. The relative importance of local retention and inter-reef dispersal of neutrally buoyant material on coral reefs. Coral Reefs 12:43-53.

Black, K., S. L. Gay, and J. C. Andrews. 1990. Residence times of neutrally-buoyant matter such as larvae, sewage or nutrients on coral reefs. Coral Reefs 9:105-114.

Born, C., O. J. Hardy, and M. H. Chevallier, S. Ossari, C. Attéké, E. J. Wickings, and M. Hossaert-McKey. 2008. Small-scale spatial genetic structure in the Central African rainforest tree species Aucoumea klaineana: a stepwise approach to infer the impact of limited gene dispersal, population history and habitat fragmentation. Molecular Ecology 17:2041-2050.

Brown, J. H., J. F. Gillooly, A. P. Allen, V. M. Savage, and G. B. West. 2004. Toward a metabolic theory of ecology. Ecology 85:1771-1789.

Campbell Grant, E. H., J. D. Nichols, W. H. Lowe, and W. F. Fagan. 2010. Use of multiple dispersal pathways facilitates amphibian persistence in stream networks. Proceedings of the National Academy of Sciences USA 107:15.

Cetina-Heredia, P., and S. R. Connolly. 2011. A simple approximation for larval retention around reefs. Coral Reefs 30:593-605.

Chapman, C. A., and S. E. Russo. 2006. Primate seed dispersal: linking behavioral ecology with forest community structure. Pages 510-525 in C. J. Campbell, A. F. Fuentes, K. C. MacKinnon, M. Panger, and S. Bearder, editors. Primates in perspective. Oxford University Press, Oxford, UK.

Connolly, S. R., and A. H. Baird. 2010. Estimating dispersal potential for marine larvae: dynamic models applied to scleractinian corals. Ecology 91:3572-3583.

Cowen, R. K., and S. Sponaugle. 2009. Larval dispersal and marine population connectivity. Annual Reviews of Marine Science 1:443-466.

Delesalle, B., and A. Sournia. 1992. Residence time of water and phytoplankton biomass in coral reef lagoons. Continental Shelf Science 12:939-949.

Dixson, D. L., G. P. Jones, P. L. Munday, M. S. Pratchett, M Srinivasan, S. Planes, and S. R. Thorrold. 2011. Terrestrial chemical cues help coral reef fish larvae locate settlement habitat surrounding islands. Ecology and Evolution 1:586595.

Edwards, H. J., I. A. Elliott, R. L. Pressey, and P. J. Mumby. 2010. Incorporating ontogenetic dispersal, ecological processes and conservation zoning into reserve design. Biological Conservation 143:457-470.

Efron, B., and R. Tibshirani. 1993. An introduction to the bootstrap. Chapman and Hall, New York, New York, USA.
Fennell, M., J. E. Murphy, C. Armstrong, T. Gallagher, and B. Osborne. 2012. Plant Spread Simulator: a model for simulating large-scale directed dispersal processes across heterogeneous environments. Ecological Modelling 230:1-10.

Figueiredo, J., and S. R. Connolly. 2012. Dispersal mediated coexistence under recruitment limitation and displacement competition. Ecological Modelling 243:133-142.

Garant, D., S. R. Forde, and A. P. Hendry. 2007. The multifarious effects of dispersal and gene flow on contemporary adaptation. Functional Ecology 21:434-443.

Gilmour, J. P., L. D. Smith, and R. M. Brinkman. 2009. Biannual spawning, rapid larval development and evidence of self-seeding for scleractinian corals at an isolated system of reefs. Marine Biology 156:1297-1309.

Graham, E. M., A. H. Baird, and S. R. Connolly. 2008. Survival dynamics of scleractinian coral larvae and implications for dispersal. Coral Reefs 27:529-539.

Grorud-Colvert, K., and S. Sponaugle. 2009. Larval supply and juvenile recruitment of coral reef fishes to marine reserves and non-reserves of the upper Florida Keys, USA. Marine Biology 156:277-288.

Harrison, P. L. 2006. Settlement competency periods and dispersal potential of scleractinian reef coral larvae. Pages 78-82 in Y. Suzuki, M. Hidaka, H. Kayanne, B. E. Casareto, K. Nadaoka, H. Yamano, and M. Tsuchiya, editors. Proceedings of the 10th International Coral Reef Symposium. Japanese Coral Reef Society, Tokyo, Japan.

Hellberg, M. E. 1994. Relationships between inferred levels of gene flow and geographic distance in a philopatric coral, Balanophyllia elegans. Evolution 48:1829-1854.

Heyward, A. J., and A. P. Negri. 1999. Natural inducers for coral larval metamorphosis. Coral Reefs 18:273-279.

Hobbs, J. P. A., G. P. Jones, and P. L. Munday. 2010. Rarity and extinction risk in coral reef angelfishes on isolated islands: interrelationships among abundance, geographic range size and specialisation. Coral Reefs 29:1-11.

Hogg, B. N., and K. M. Daane. 2010. The role of dispersal from natural habitat in determining spider abundance and diversity in California vineyards. Agriculture, Ecosystems and Environment 135:260-267.

Hubbell, S. 2001. The unified neutral theory of biodiversity and biogeography. Princeton University Press, Princeton, New Jersey, USA.

Jones, G. P., G. R. Almany, G. R. Russ, P. F. Sale, R. S. Steneck, M. J. H. van Oppen, and B. L. Willis. 2009. Larval retention and connectivity among populations of corals and reef fishes: history, advances and challenges. Coral Reefs 28:307-325.

Kininmonth, S. J., G. De'ath, and H. P. Possingham. 2010. Graph theoretic topology of the Great but small Barrier Reef world. Theoretical Ecology 3:75-88.

Kraines, S. B., T. Yanagi, M. Isobe, and H. Komiyama. 1998. Wind-wave driven circulation on the coral reef at Bora Bay, Miyako Island. Coral Reefs 17:133-143.

Kramer, H. A. C., D. M. Montgomery, V. M. Eckhart, and M. A. Geber. 2011. Environmental and dispersal controls of an annual plant's distribution: How similar are patterns and apparent processes at two spatial scales? Plant Ecology 212:1887-1899.

Lang, J. 1973. Interspecific aggression by scleractinian corals. 2 . Why the race is not only to the swift. Bulletin of Marine Science 23:260-279.

Lang, J. C., and E. A. Chornesky. 1990. Competition between scleractinians reef corals - a review of mechanisms and effects. Pages 209-252 in Z. Dubinsky, editor. Coral reefs. Ecosystems of the world. Volume 25. Elsevier, Amsterdam, The Netherlands.

Leis, J. M. 1982. Nearshore distributional gradients of larval fish (15 taxa) and planktonic crustaceans (6 taxa) in Hawaii. Marine Biology 72:89-97. 
Leis, J. M., K. J. Wright, and R. N. Johnson. 2007. Behaviour that influences dispersal and connectivity in the small, young larvae of a reef fish. Marine Biology 153:103-117.

McQuaid, C. D., and T. E. Phillips. 2000. Limited wind-driven dispersal of intertidal mussel larvae: in situ evidence from the plankton and the spread of the invasive species Mytilus galloprovincialis in South Africa. Marine Ecology Progress Series 201:211-220.

Merritt, D. M., C. Nilsson, and R. Jansson. 2010. Consequences of propagule dispersal and river fragmentation for riparian plant community diversity and turnover. Ecological Monographs 80:609-626.

Morse, A. N. C., K. Iwao, M. Baba, K. Shimoike, T. Hayashibara, and M. Omori. 1996. An ancient chemosensory mechanism brings new life to coral reefs. Biological Bulletin 191:149-154.

Muko, S., and Y. Iwasa. 2003. Incomplete mixing promotes species coexistence in a lottery model with permanent spatial heterogeneity. Theoretical Population Biology 64:359-368.

Nathan, R., and H. C. Muller-Landau. 2000. Spatial patterns of seed dispersal, their determinants and consequences for recruitment. Trends in Ecology and Evolution 15:278-85.

Nozawa, Y., and P. L. Harrison. 2002. Larval settlement patterns, dispersal potential, and the effect of temperature on settlement of larvae of the reef coral, Platygyra daedalea, from the Great Barrier Reef. Pages 409-416 in Y. Suzuki, M. Hidaka, H. Kayanne, B. E. Casareto, K. Nadaoka, H. Yamano, and M. Tsuchiya, editors. Proceedings of the 10th International Coral Reef Symposium. Japanese Coral Reef Society, Tokyo, Japan.

Paris, C. B., and R. K. Cowen. 2004. Direct evidence of a biophysical retention mechanism for coral reef fish larvae. Limnology and Oceanography 49:1964-1979.

Saavedra-Sotelo, N., L. Calderon-Aguilera, H. Reyes-Bonilla, R. López-Pérez, P. Medina-Rosas, and A. Rocha-Olivares. 2011. Limited genetic connectivity of Pavona gigantea in the Mexican Pacific. Coral Reefs 30:677-686.

Salomon, Y., S. R. Connolly, and L. Bode. 2010. Effects of asymmetric dispersal on the coexistence of competing species. Ecology Letters 13:432-441.
Sentis, A., J.-L. Hemptine, and J. Brodeur. 2012. Using functional response modeling to investigate the effect of temperature on predator feeding rate and energetic efficiency. Oecologia 169:1117-1125.

Sexton, J. P., P. J. McIntyre, A. L. Angert, and K. J. Rice. 2009. Evolution and ecology of species range limits. Annual Review of Ecology, Evolution, and Systematics 40:415-436.

Stimson, J. 1985. The effect of shading by the table coral Acropora hyacinthus on understory corals. Ecology 66:40-53.

Swearer, S. E., J. S. Shima, M. E. Hellberg, S. R. Thorrold, G. P. Jones, D. R. Robertson, S. G. Morgan, K. A. Selkoe, G. M. Ruiz and R. R. Warner. 2002. Evidence of selfrecruitment in demersal marine populations. Bulletin of Marine Science 70(Supplement):251-271.

Tarinville, B., E. Deleersnijder, and J. Rancher. 1997. The water residence time in Mururoa atoll lagoon: sensitivity analysis of a three-dimensional model. Coral Reefs 16:193203.

van Oppen, M. J. H., A. Lutz, G. De'ath, L. Peplow, and S. Kininmonth. 2008. Genetic traces of recent long-distance dispersal in a predominantly self-recruiting coral. PLoS One 3(10):e3401.

Vanschoenwinkel, B., S. Gielen, M. Seaman, and L. Brendonck. 2008. Any way the wind blows - frequent wind dispersal drives species sorting in ephemeral aquatic communities. Oikos 117:125-134.

Whitaker, K. 2004. Non-random mating and population genetic subdivision of two broadcasting corals at Ningaloo Reef, Western Australia. Marine Biology 144:593-603.

Whitfield, P. E., J. A. Hare, A. W. David, S. L. Harter, R. C. Munoz, and C. M. Addison. 2007. Abundance estimates of the Indo-Pacific lionfish Pterois volitans/miles complex in the Western North Atlantic. Biological Invasions 9:53-64.

Wilson, J. R. U., E. E. Dormontt, P. J. Prentis, A. J. Lowe, and D. M. Richardson. 2009. Something in the way you move: dispersal pathways affect invasion success. Trends in Ecology and Evolution 24:136-144.

Wright, K. J., D. M. Higgs, A. J. Belanger, and J. M. Leis. 2005. Auditory and olfactory abilities of pre-settlement larvae and post-settlement juveniles of a coral reef damselfish (Pisces: Pomacentridae). Marine Biology 147:1425-1434.

\section{Supplemental Material}

\section{Appendix A}

Details on the reefs of the Great Barrier Reef used in this study described by Black et al. (1990) (Ecological Archives E094-057-A1).

\section{Appendix B}

Date and time of spawning, mean egg size, time to motility, and the collection location of 20 broadcast spawner species (Ecological Archives E094-057-A2).

\section{Supplement}

Data and code for the survival and competence dynamics model and estimate of proportion of larvae retained (Ecological Archives E094-057-S1). 